\title{
ACTIVATION OF AIR-STABLE ZERO-VALENT IRON NANOPARTICLES: COMPARISION OF DIFFERENT APPROACHES
}

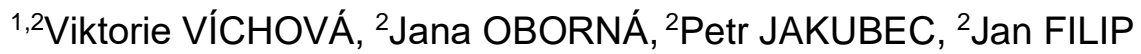 \\ ${ }^{1}$ Department of Experimental Physics, Faculty of Science, Palacký University in Olomouc, \\ Czech Republic, EU, viktorie.vichova@upol.cz \\ ${ }^{2}$ Regional Centre of Advanced Technologies and Materials, Palacký University in Olomouc, \\ Czech Republic, EU
}

https://doi.org/10.37904/nanocon.2020.3721

\begin{abstract}
Nanoscale zero-valent iron ( $\mathrm{nZVI}$ ) particles represent a strong reducing agent which makes them highly promising in the process of degradation of organic compounds such as persistent chlorinated compounds (e.g. chlorinated ethylenes) as well as immobilisation of inorganic pollutants (e.g. hazardous elements). In this contribution, we compare several types of activation procedures to restore the reactivity of air-stable nZVI particles. Different approaches to increase the reactivity of $n Z V I$ particles have been tested for hexavalent chromium $(\mathrm{Cr}(\mathrm{VI}))$ removal. The study was supplemented by complex characterisation of $\mathrm{nZVI}$ particles including electrochemical impedance spectroscopy, X-ray powder diffraction, transmission electron microscopy and specific surface area measurement. Based on experiments of contaminant removal capacity and the characterization of activated nZVI particles, we can conclude that the short-time high-temperature activation process is the most efficient.
\end{abstract}

Keywords: Air-stable zero-valent iron nanoparticles, activation process, hexavalent chromium removal, groundwater remediation

\section{INTRODUCTION}

Nanoscale zero-valent iron (nZVI) particles are typically used for removal of environmentally hazardous substances (e.g. hazardous elements) because of their high reactivity and the strong reducing effect. During the chemical reduction, nZVI particles reduce pollutants to less toxic products and nanoparticles themselves are oxidized to environmentally benign iron oxides. The nanoscale of the particles leads to their high reactivity and allows them to migrate in aqueous media easily. The high specific surface area of nZVI particles causes their high reactivity and also a high sorption capacity. Reactivity of nZVI particles could be further controlled by modifying their surface and/or by combination with other abiotic or biotic processes [1-3].

The most common modification of nZVI surface is to create a compact oxide shell. Such nanoparticles are air-stable containing a metallic-iron core and a compact oxide shell [4]. The oxide shell is formed by iron oxides protecting $\mathrm{nZVI}$ core against fast oxidation by oxygen leading to their easier transport, storage and manipulation. On the other hand, this shell leads to the decrease of the $\mathrm{nZVI}$ reactivity when they are used for contaminant removal. A process called the activation of air-stable zero-valent iron nanoparticles is essential for recovering their reactivity with contaminants during the remediation process [5].

In this paper, we compared a traditional activation [5] with two new approaches to the activation of air-stable zero-valent iron nanoparticles. Evaluation of changes in their reactivity was monitored by hexavalent chromium reduction to trivalent chromium $[6,7]$. 


\section{MATERIALS AND METHODS}

\subsection{Chemicals}

NANOFER STAR (air-stable zero-valent iron nanoparticles consisting of metallic iron core and thin oxide shell) were purchased from NANOIRON, Ltd. (Czech Republic). The solution with an initial $\mathrm{Cr}(\mathrm{VI})$ concentration equal to $10 \mathrm{mg} / \mathrm{L}$ was prepared from potassium dichromate $\left(\mathrm{K}_{2} \mathrm{Cr}_{2} \mathrm{O}_{4}\right.$, Sigma Aldrich, USA) with the minimum purity of $98 \%$. Chemicals used for electrochemical impedance spectroscopy: phosphate buffer solution (Penta s.r.o, Czech Republic) and potassium ferricyanide(III) (Sigma Aldrich, USA). Solutions for colourimetric test contained 1,5-diphenylcarbazide (Sigma Aldrich, USA) and $0.04 \mathrm{~mol}$ solution of $\mathrm{HCl}$ (Lach-Ner, Czech Republic).

\subsection{Characterization Techniques}

Microscopy characterization was performed on a transmission electron microscope (TEM) JEOL JEM 2100 at $200 \mathrm{kV}$ of accelerating voltage. To each sample in small Eppendorf tube was added ethanol (methylated ethanol, Tereos TTD, Czech Republic) and was not followed by sonication. Suspensions were dropped on carbon grid and dried on air. The average thickness of the oxide layer on nZVI particles was measured from TEM images using ImageJ software (version 1.53e, Wayne Rasband, USA).

Electrochemical impedance spectroscopy (EIS) was measured in a three-electrode configuration, in which the glassy carbon electrode modified with iron-based samples, platinum wire electrode, and $\mathrm{Ag} / \mathrm{AgCl}(3 \mathrm{M} \mathrm{KCl})$ electrode (all purchased from 2THETA ASE s.r.o., Český Těšín, Czech Republic) served as working, counter, and reference electrodes, respectively. EIS experiments were carried out using a Metrohm Autolab PGSTAT128N potentiostat/galvanostat (Metrohm Autolab B.V., Netherlands). Phosphate buffer solution (PBS, pH 7) was used as a supporting electrolyte containing $5 \mathrm{mmol} / \mathrm{L} \mathrm{K}_{3}\left[\mathrm{Fe}(\mathrm{CN})_{6}\right]$ as a redox probe. All experiments were carried out at room temperature $\left(22 \pm 2{ }^{\circ} \mathrm{C}\right)$. All EIS spectra were collected using a $5 \mathrm{mV}$ amplitude and were recorded over the frequency range from $0.1 \mathrm{~Hz}$ to $10 \mathrm{kHz}$ using the half-wave potential of potassium ferricyanide(III) (0.2 V). The glassy carbon electrode (GCE) was modified as follows: a $10 \mu \mathrm{L}$ drop of a powder suspension $(2 \mathrm{mg} / \mathrm{mL})$ was drop-coated onto the surface of the GCE electrode and allowed to dry at ambient temperature to form a thin film.

For measurement of the specific surface area, samples were dried under a nitrogen atmosphere in a glove box (SylaTech $\mathrm{GmbH}$, Germany). The specific surface area of samples was measured using a surface area and porosity analyser Autosorb IQ (Quantachrome, USA) and determined by Brunauer-Emmett-Teller (BET) theory. Process of degassing was held at a temperature of $130{ }^{\circ} \mathrm{C}$ for 13 hours.

The X-ray powder diffraction (XRD) was measured employing X'Pert PRO diffractometer (Malvern Panalytical, UK) equipped with Co radiation source, programmable divergence and diffracted beam anti-scatter slits, and X Celerator detector. The wet samples were dropped on a zero-background silicon slide and covered with Myllar foil to protect them against drying. Every pattern was captured by the measurement of six fast repetitive scans ( $5 \mathrm{~min}$ each) in the range between 5 and $105^{\circ} 2$ Theta. NANOFER STAR $\mathrm{nZVI}$ particles (NFSTAR) were measured as a typical dry powder sample, i.e., the sample was prepared by the back-loading method of the sample holder and the pattern was measured as a single scan in the range between 5 and $105^{\circ} 2$ Theta. The data were processed employing High Score Plus software in conjunction with PDF-4+ and ICSD databases.

\subsection{Activation Process}

Three different approaches of activation of zero-valent iron nanoparticles were examined in this study. To obtain nZVI slurries, nZVI particles were added to deionized water leading to the final concentration of $250 \mathrm{~g} / \mathrm{L}$ nZVI particles to distilled water. Before the activation process, nZVI slurries were dispersed using T 10 basic ULTRA-TURRAX (IKA, Germany) for 2 minutes at $11000 \mathrm{rpm}$. 
The first method of activation of nZVI particles in water for 24 hours was adopted from Ribas et al. [5]. Briefly, $5 \mathrm{~g}$ of $\mathrm{nZVI}$ particles was added to $20 \mathrm{~mL}$ of distilled water in $40 \mathrm{~mL}$ glass vial and dispersed. The activation process was held at the room temperature for 24 hours (sample labelled as A_TIME).

The second approach utilized heating of ferromagnetic $\mathrm{nZVI}$ particles in an electromagnetic field (EMF) (samples labelled as A_EMF) [8,9]. nZVI suspension ( $10 \mathrm{~g}$ of $\mathrm{nZVI}$ and $40 \mathrm{~mL}$ of distilled water in $60 \mathrm{~mL}$ glass vial) with the final concentration of $n Z V I$ equal $250 \mathrm{~g} / \mathrm{L}$ was dispersed. Then, glass vial was placed inside the copper coil of the induction heating device CX-2015A (Chengdu Jinkezhi Electronic Co., China). The activation process was performed for 30 minutes with the regulation of secondary current in the coil equal $310 \mathrm{~A}$.

To simulate the heating effect of the electromagnetic field on $\mathrm{nZVI}$ particles (samples labelled as A_TEMP), the third method of zero-valent iron nanoparticles activation was tested The nZVI suspension was prepared by the same approach as in the first method. Glass vial was placed in a water bath and heated for 35 minutes with a setting of the temperature of water bath equal to $105^{\circ} \mathrm{C}$ (sample labelled as A_TEMP). Heating time and temperature rate were chosen according to temperatures reached during the activation process in EMF.

All experiments were conducted in triplicates. Measurements of temperature, $\mathrm{pH}$ and oxidation-reduction potential (ORP) were done for every sample before and after the process of activation (Multi 3410, WTW, Germany). ORP values normalized to standard hydrogen electrode (SHE) adding $+207 \mathrm{mV}$ (for $25^{\circ} \mathrm{C}$, sample A_TIME), $+188 \mathrm{mV}$ (for $50^{\circ} \mathrm{C}$, sample A_EMF) and $+184 \mathrm{mV}$ (for $55^{\circ} \mathrm{C}$, sample A_TEMP).

\subsection{Hexavalent Chromium Removal}

To determine the reactivity of treated $\mathrm{nZVI}$ particles for contaminant removal, batch experiments with model contaminant $\mathrm{Cr}(\mathrm{VI})$ were held. Slurries with $\mathrm{nZVI}$ particles were dispersed after the activation process in the same procedure as described in Section 2.1. The initial concentration of $\mathrm{Cr}(\mathrm{VI})$ was $10 \mathrm{mg} / \mathrm{L}$ and concentration of $\mathrm{nZVI}$ was equal to $2 \mathrm{~g} / \mathrm{L}$. The $\mathrm{pH}$ of $\mathrm{Cr}(\mathrm{VI})$ solution was adjusted to 7 using $0.4 \mathrm{~mol} \mathrm{HCl}$ (Lach-Ner, Czech Republic). Experiments were conducted in $40 \mathrm{~mL}$ glass vials at room temperature (RT). Experiments for $\mathrm{Cr}(\mathrm{VI})$ removal by $\mathrm{nZVI}$ particles were managed for 1, 2.5, 5, 15, 30 and 60 minutes, 24, 48 and 72 hours. Blank samples without nZVI particles were measured in the time period of $0,1,24,48$ and 72 hours. Samples were shaken at the horizontal shaker Unimax 2010 (Heidolph, Germany) at $300 \mathrm{rpm}$. Samples were filtrated using PTFE membrane filters with $0.1 \mu \mathrm{m}$ pore size (Whatman, United Kingdom). Colourimetric test EPA METHOD 7196A was performed to measure the residual concentration of $\mathrm{Cr}(\mathrm{VI})$ in samples using UV-Visible spectrophotometer (Biochrom WPA Lightwave II, UK) at wavelength $\lambda=542 \mathrm{~nm}$.

\section{RESULTS AND DISCUSSION}

\subsection{Characterization of Nanoparticles Before and after Activation Process}

TEM images of nZVI particles before and after the activation process are presented in Figure 1. Initial nZVI particles (samples labelled as NFSTAR) show a uniform oxide layer on their surface with a thickness approximately $4.3 \mathrm{~nm}$ (Table 1). The oxide shell of activated nanoparticles reveals substantial changes as can be seen from Figure 1. This is mainly reflected in the presence of significant fractures and defect of the oxide shell for all three activated samples. Such changes are accompanied by the increased thickness of the oxide layer compared to un-activated nZVI (ranging from 5.1 to $5.6 \mathrm{~nm}$ ).

Charge transfer resistance $\left(R_{\mathrm{ct}}\right)$ values obtained from electrochemical impedance spectroscopy (EIS) are shown in Figure 2. The average value of $R_{c t}$ of unactivated nZVI particles (NFSTAR) is the lowest compared to activated samples. During the activation process, the value of $R_{c t}$ increased. This change is significant for the growth of the oxide shell but also for its structural changes and growth of other material phases such as e.g. iron hydroxides. This increased thickness of the oxide layer is also observable in TEM images (Figure 1). 
The changes in the specific surface area of $\mathrm{nZVI}$ particles during the activation process are shown in Table 1. This value increased for all types of the activation process and is comparable for all activated samples.

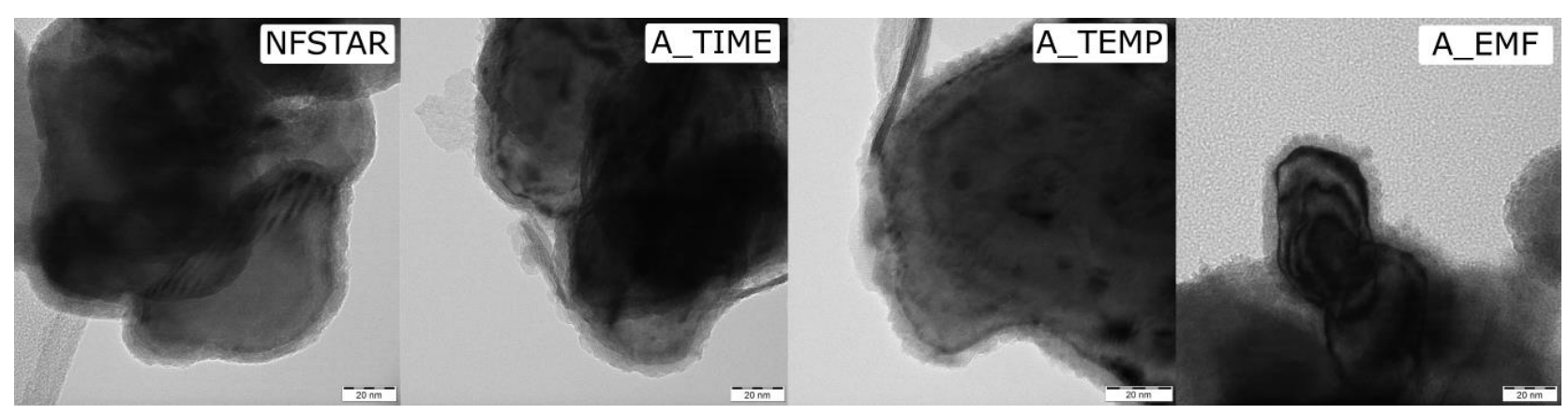

Figure 1 Comparison of TEM images of initial and activated nZVI nanoparticles

Table 1 The average thickness of the oxide layer on nZVI particles measured from TEM images and the average specific surface area of $\mathrm{nZVI}$ particles before and after the activation process

\begin{tabular}{|c|c|c|c|}
\hline Sample & $\begin{array}{c}\text { Average thickness of the } \\
\text { oxide layer }(\mathbf{n m})\end{array}$ & $\begin{array}{c}\text { Number of } \\
\text { measurements }\end{array}$ & $\begin{array}{c}\text { SSA } \\
\left(\mathbf{m}^{\mathbf{2}} \cdot \mathbf{g}^{-1}\right)\end{array}$ \\
\hline NFSTAR & $4.3 \pm 0.6$ & 93 & 20.8 \\
\hline A_TIME & $5.3 \pm 0.7$ & 53 & $37.3 \pm 5.6$ \\
\hline A_TEMP & $5.1 \pm 0.9$ & 57 & $30.5 \pm 6.0$ \\
\hline A_EMF & $5.6 \pm 0.9$ & 74 & $36.3 \pm 8.6$ \\
\hline
\end{tabular}

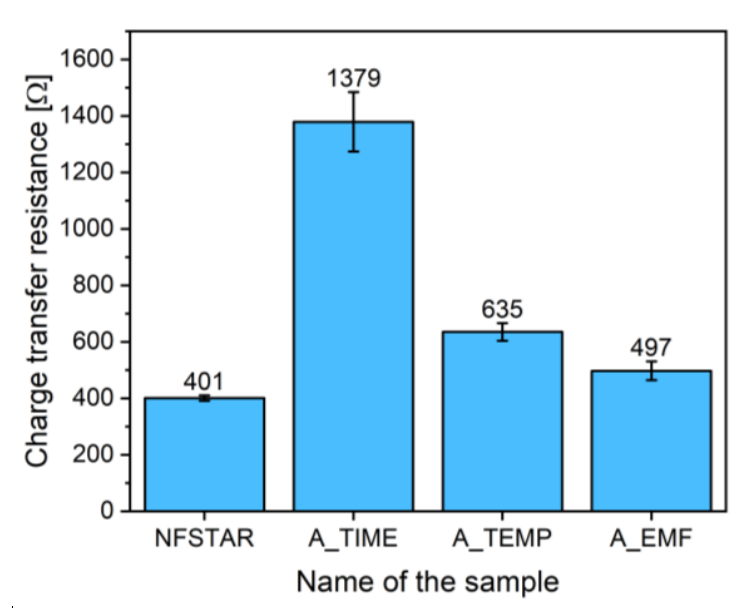

Figure 2 Average charge transfer resistance ( $\left.R_{c t}\right)$ of un-activated (NFSTAR) and activated nZVI particles measured by EIS

XRD patters of un-activated and activated nZVI particles are shown in Figure 3. In is worth to note, that XRD records of activated samples and NFSTAR sample, do not exhibit any significant crystallographic changes or changes in phase composition.

Evolution of $\mathrm{pH}$ and ORP values proved enhanced reactivity of $\mathrm{nZVI}$ particles after the activation process. Increasing values of $\mathrm{pH}$ and decreasing values of ORP (Table 2) are significant for higher reactivity of zero-valent iron nanoparticles in an aqueous environment. Comparing different approaches of activation of $n Z \mathrm{VI}$ particles, there is only a small increase of $\mathrm{pH}$ value and slower decrease of ORP for $\mathrm{nZVI}$ particles activated for 24 hours (A_TIME) compared to other two activation procedures. For activation in the water bath 
(A_TEMP) and EMF (A_EMF), the change of $\mathrm{pH}$ and ORP have similar trend and are more significant than for method A_TIME. While the activation process A_TIME was held at the RT, the other two samples reached temperatures up to $95{ }^{\circ} \mathrm{C}$ during the activation process. According to this, it can be concluded that a higher temperature is increasing the reactivity of $\mathrm{nZVI}$ particles. The changes in the oxide shell morphology seem to be analogous to the oxide shells prepared at elevated temperatures by Kašlík et al. in [10] leading to the same changes in reactivity.

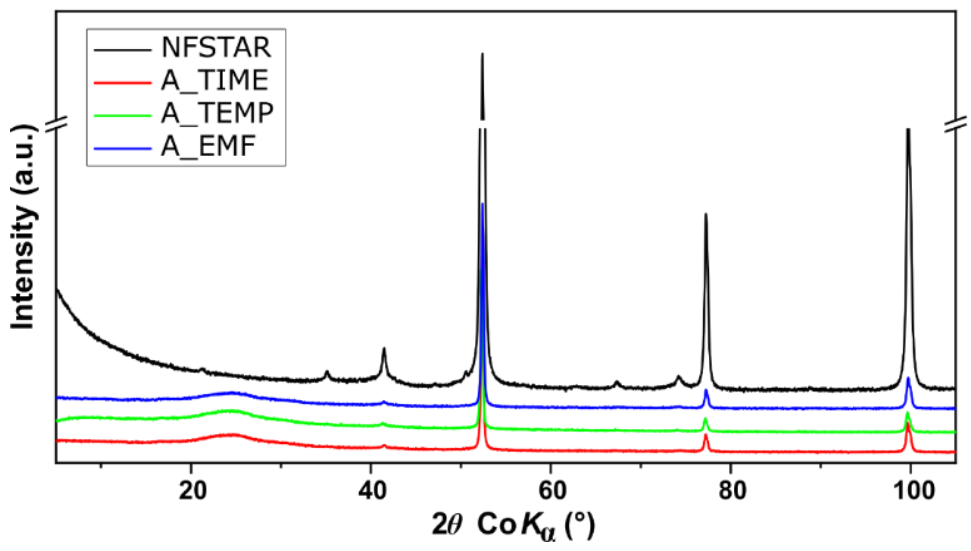

Figure 3 XRD patterns of initial and activated nZVI nanoparticles. NFSTAR was measured in a different mode which is leading to higher peak intensities (counts) compared to activated samples

Table $2 \mathrm{pH}$ and ORP development during the activation process. Data logged before and after the activation processes in nZVI suspensions (Multi 3410, WTW, Germany)

\begin{tabular}{|c|c|c|c|c|}
\hline \multirow{2}{*}{ Sample } & \multicolumn{2}{|c|}{ Average ORP $(\mathrm{mV}$ SHE) } & \multicolumn{2}{c|}{ Average $\mathrm{pH}$} \\
\cline { 2 - 5 } & Before & After & Before & After \\
\hline A_TIME & $270 \pm 109$ & $-38 \pm 1$ & $6.91 \pm 0.04$ & $7.2 \pm 0.4$ \\
\hline A_TEMP & $143 \pm 40$ & $-125 \pm 32$ & $6.90 \pm 0.08$ & $8.5 \pm 0.2$ \\
\hline A_EMF & $263 \pm 75$ & $-269 \pm 12$ & $6.9 \pm 0.2$ & $8.5 \pm 0.2$ \\
\hline
\end{tabular}

\subsection{Evaluation of $\mathrm{Cr}(\mathrm{VI})$ Removal}

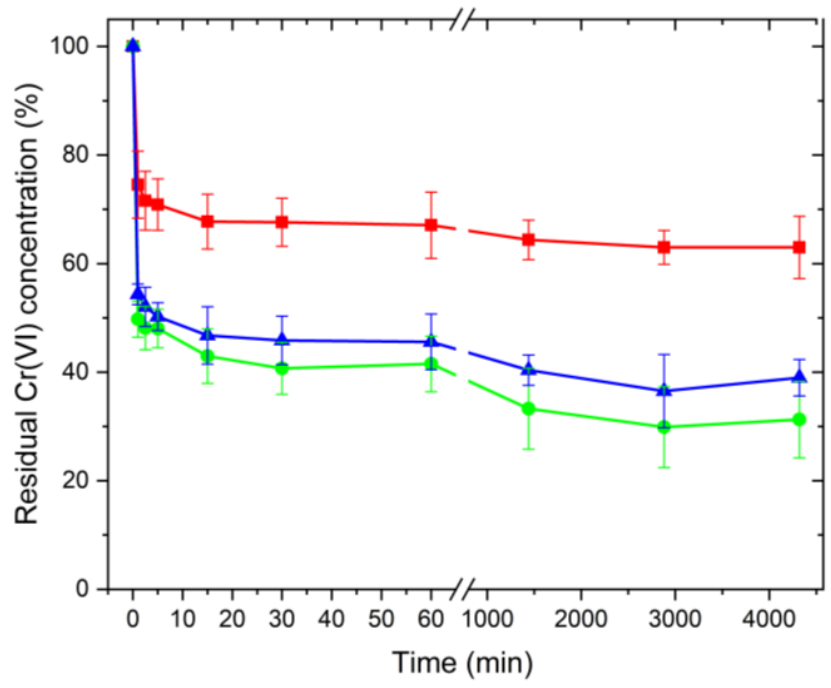

Figure 4 The change of residual concentration of $\mathrm{Cr}(\mathrm{VI})$ in time for $\mathrm{nZVI}$ particles activated in three different approaches. Initial concentration of $\mathrm{Cr}(\mathrm{VI})$ was equal to $10 \mathrm{mg} / \mathrm{L}$ 
The trend of the residual concentration of $\mathrm{Cr}(\mathrm{VI})$ in time for $\mathrm{nZVI}$ particles activated in three different approaches is shown in Figure 4. The lowest reaction rate corresponds to A_TIME nZVI particles with removal capacity of $37 \%$ of $\mathrm{Cr}(\mathrm{VI})$ after 3 days. However, the $\mathrm{Cr}(\mathrm{VI})$ removal capacity was higher for nZVI particles activated at higher temperatures reaching $69 \%$ (A_TEMP) and $61 \%$ (A_EMF) of removed $\mathrm{Cr}(\mathrm{VI})$ after 3 days.

\section{CONCLUSION}

Three different approaches of the activation process were performed on air-stable zero-valent iron nanoparticles to recover their reactivity. The activation process of nZVI particles commonly used in practice was compared with two new methods of activation performed at high temperatures for the period of 30-35 minutes. Short-time high-temperature methods revealed an increase of the contaminant removal capacity tested on $\mathrm{Cr}(\mathrm{VI})$ reduction. In all cases, the oxide shell of nanoparticles changed its character with increasing specific surface area and more defects leading to their higher reactivity without significant structural changes or phase composition of nZVI particles.

\section{ACKNOWLEDGEMENTS}

This research was supported by the ERDF project No. CZ.02.1.01/0.0/0.0/16_019/0000754 of the Ministry of Education, Youth and Sports of the Czech Republic, and by the project No. FV30034 from Ministry of Industry and Trade of the Czech Republic. The authors also gratefully acknowledge the financial support from the internal IGA grant of Palacký University (IGA_PrF_2020_034). Authors thank Josef Kašlík for XRD measurement and Jana Stráská for TEM images.

\section{REFERENCES}

[1] SUN, Y. P., LI, X. Q., CAO, J., ZHANG, W. X., WANG, H. P. Characterization of zero-valent iron nanoparticles. Advances in colloid and interface science. 2006, vol. 120, no. 1-3, pp. 47-56.

[2] ZOU, Y., WANG, X., KHAN, A., WANG, P., LIU, Y., ALSAEDI, A., HAYAT, T., WANG, X. Environmental remediation and application of nanoscale zero-valent iron and its composites for the removal of heavy metal ions: a review. Environmental science \& technology. 2016, vol. 50, no. 14, pp. 7290-7304.

[3] O'CARROLL, D., SLEEP, B., KROL, M., BOPARAI, H., KOCUR, C. Nanoscale zero valent iron and bimetallic particles for contaminated site remediation. Advances in Water Resources. 2013, vol. 51, pp. 104-122.

[4] KIM, H. S., AHN, J. Y., HWANG, K. Y., KIM, I. K., HWANG, I. Atmospherically stable nanoscale zero-valent iron particles formed under controlled air contact: characteristics and reactivity. Environmental science \& technology. 2010, vol. 44, no. 5, pp. 1760-1766.

[5] RIBAS, D., ČERNÍK, M., BENITO, J. A., FILIP, J., MARTI, V. Activation process of air stable nanoscale zerovalent iron particles. Chemical Engineering Journal. 2017, vol. 320, pp. 290-299.

[6] DI PALMA, L., PETRUCCI, E., VERDONE, N., VILARDI, G. Iron Nanoparticles for Cr (VI) Removal from Contaminated Soil. In: LITTER, M. I., QUICI, N., MEICHTRY, M. Iron Nanomaterials for Water and Soil Treatment. Jenny Stanford Publishing, 2018, pp. 201-231.

[7] LI, S., WANG, W., LIANG, F., ZHANG, W. X. Heavy metal removal using nanoscale zero-valent iron (nZVI): theory and application. Journal of hazardous materials. 2017, vol. 322, pp. 163-171.

[8] PHENRAT, T., THONGBOOT, T., LOWRY, G. V. Electromagnetic induction of zerovalent iron (ZVI) powder and nanoscale zerovalent iron ( $\mathrm{NZVI)} \mathrm{particles} \mathrm{enhances} \mathrm{dechlorination} \mathrm{of} \mathrm{trichloroethylene} \mathrm{in} \mathrm{contaminated}$ groundwater and soil: Proof of concept. Environmental science \& technology. 2016, vol. 50, no. 2, pp. $872-880$.

[9] PHENRAT, T., LOWRY, G. V. Nanoscale zerovalent iron particles for environmental restoration. Springer, 2019.

[10] KAŠLÍK, J., KOLAŘíK, J., FILIP, J., MEDŘíK, I., TOMANEC, O., PETR, M., .. \& TRATNYEK, P. G. Nanoarchitecture of advanced core-shell zero-valent iron particles with controlled reactivity for contaminant removal. Chemical Engineering Journal. 2018, vol. 354, pp. 335-345. 